\title{
Favouring a Disunited Kingdom? How Negative Perceptions of the EU- Referendum Relate to Individual Mobility and Collective Action Considerations
}

\author{
Lara Ditrich $^{\text {a }}$, Edit Z. Gedeon ${ }^{\text {ab }}$, Kai Sassenberg ac \\ [a] Social Processes Lab, Leibniz-Institut für Wissensmedien, Tübingen, Germany. [b] School of Psychological Sciences and Health, University of Strathclyde, \\ Glasgow, United Kingdom. [c] University of Tübingen, Tübingen, Germany.
}

Journal of Social and Political Psychology, 2021, Vol. 9(1), 37-51, https://doi.org/10.5964/jspp.5547

Received: 2020-03-23 • Accepted: 2020-10-25 • Published (VoR): 2021-02-19

Handling Editor: Sammyh Khan, Örebro University, Örebro, Sweden

Corresponding Author: Lara Ditrich, Social Processes Lab, Leibniz-Institut für Wissensmedien, Schleichstr. 6, 72076 Tübingen, Germany. E-mail: l.ditrich@iwm-tuebingen.de

Supplementary Materials: Data, Materials [see Index of Supplementary Materials]

\begin{abstract}
One consequence of the EU-referendum's pro-Brexit outcome was a renewed call for Scottish independence. Supporting this call can be construed as a form of collective action Scots may engage in. However, Scots may also consider individual mobility strategies including - in extreme cases - emigration. The current research investigated how identity-dynamics relate to these identity management strategies in post-referendum Scotland. We found a positive association between perceiving the EU-referendum as having violated expectations and considering individual mobility responses, mediated by identity subversion (i.e., the perception that the referendum results fundamentally changed the UK's identity). Furthermore, we found that perceiving the EU-referendum as having violated expectations was related to higher collective action intentions, mediated by disidentification from UK citizens. Taken together, these findings underscore the pervasive role social identity processes play in shaping political decisions and individual behaviour.
\end{abstract}

\section{Keywords}

disidentification, identity subversion, collective action, individual mobility, Brexit

\section{Non-Technical Summary}

\section{Background}

In the referendum in June 2016, the citizens of the United Kingdom (UK) had the possibility to decide whether their country should remain in or leave the European Union (EU). Overall, 51.9\% voted to leave the EU, but the referendum outcome differed markedly between the constituent countries within the UK. One consequence of the EU-referendum's outcome was a renewed call for Scottish independence. A second consequence was a marked increase in the number of people who emigrated from the UK to, or were granted citizenship in, another country within the EU.

\section{Why was this study done?}

Supporting a second referendum for Scottish independence is an action that aims at changing the position of a group as a whole (i.e., reflects collective action). Emigrating from the UK, in turn, represents an individual response that only changes one's own situation (i.e., reflects individual mobility). In the present study, we investigated psychological processes that could 
underly these reactions to the EU-referendum. Specifically, we focused on how Scots' perceptions of the referendum process relate to (a) their perceptions of the UK as a whole and (b) how they feel about being UK-citizens. Moreover, we investigated how these aspects relate to considering emigration and supporting a new campaign for Scottish independence.

\section{What did the researchers do and find?}

We conducted a survey with 202 respondents living in Scotland. We assessed how respondents perceived the EU-referendum process, whether they had the impression that the UK had fundamentally changed due to the referendum outcome, how they felt about being a citizen of the UK, and to what extent they considered emigration and supporting a new independence campaign. Our results show that the more Scots perceived the referendum process as having violated their expectations of political processes in the UK, the more likely they were to consider emigration and the more they intended to support a campaign in favour of Scottish independence. Furthermore, our results suggest that the impression that the UK as a whole has changed underlies the relation between perceptions of the referendum process as having violated expectations and emigration considerations, whereas feeling negatively about being a UK-citizen underlies the relation between perceptions of the referendum process as having violated expectations and support for Scottish independence.

\section{What do these findings mean?}

The present study suggests that three factors need to be considered when trying to understand how people react to geopolitical events. The first is how they perceive the processes related to this event. If these processes are perceived as violating expectations, intentions to leave the country or to support separatist movements may be more pronounced. For policy makers seeking to avoid these reactions, this means that they should prevent their behaviours from being perceived as violating expectations. The second and third factor that need to be considered are an individual's perception of the group they live in and their personal relation to this group. This suggests that identity-related dynamics may not only shape voting behaviour, but political processes more broadly.

On June 23, 2016, the citizens of the United Kingdom (UK) had the possibility to decide whether their country should remain in or leave the European Union (EU). Overall, 51.9\% voted to leave the EU (Electoral Commission, 2018). There were, however, large differences between the regions. While most voters in England (53.4\%) voted "leave", $62 \%$ of voters in Scotland voted "remain" (BBC News, 2018). Interestingly, Scotland's continued membership in the EU (and the benefits thereof) had been used to discourage voting for Scottish independence in the referendum held on this issue in 2014 (e.g., GOV.UK, 2014). Thus, it is unsurprising that the EU-referendum's outcome led to a call for a second referendum on Scottish independence (still pursued by the Scottish parliament; BBC News, 2020a). An additional consequence of the EU-referendum's outcome was a marked increase in the number of people who emigrated from the UK to, or were granted citizenship in, another country within the EU: In 2017, six times more Brits received a passport for a different EU country than in 2015, and emigration numbers reached a ten-year high, with many claiming Brexit as the reason for leaving the UK (Auer \& Tetlow, 2019).

But why should Brexit impact people's views on Scottish independence? And why should it motivate them to emigrate? While political and economic reasons undoubtedly play a major role, herein we will focus on a psychological aspect of the post-referendum situation in the UK: the identity-related dynamics involved. Specifically, we will study Scots as a group within the UK and explore the relation between these identity dynamics and the reactions Scots consider.

In this endeavour, we will focus on perceptions of identity subversion and disidentification from the citizens of the UK. Moreover, we will test how these are related to two types of identity management strategies: individual mobility (i.e., considering emigration) and collective action (i.e., intentions to support a new Scottish independence campaign). Thereby, we strive to shed light on the correlates of group members' consideration of different identity management strategies in an intriguing setting - one in which individuals are faced with a highly impactful, yet controversial geopolitical decision. To this end, we will address two aspects in our introduction. 
First, we will summarize research we deem relevant to the current case on group schisms (e.g., Sani, 2008; Sani \& Todman, 2002), social identity management strategies (e.g., Blanz, Mummendey, Mielke, \& Klink, 1998; Ellemers, 1993), and disidentification (e.g., Becker \& Tausch, 2014; Matschke \& Sassenberg, 2010). We will also explore the connections between concepts stemming from these related, but to date separate areas of research, as a first step to bridging the divide between them.

Second, we will apply the predictions derived from these fields of research to Scots' situation after the EU-referendum. Thereby, we seek to extend the current psychological research on Brexit, which to date has primarily focused on the (often identity-related) antecedents of people's decision to vote in favour of or against leaving the EU (e.g., Abrams \& Travaglino, 2018; Lewis \& de Wit, 2019; Manners, 2018; Smith, 2019; Swami, Barron, Weis, \& Furnham, 2018; Van de Vyver, Leite, Abrams, \& Palmer, 2018), on the outcomes' consequences for individual well-being (Sirois \& Iyer, 2018), and on people's preferences for the Brexit negotiations (Peitz, Dhont, \& Seyd, 2018).

\section{Identity-Dynamics Related to Considering Individual Mobility}

Groups strongly influence their members by defining what attitudes they hold, which values are important to them, and how they behave (e.g., Sherif, 1961; Terry \& Hogg, 1996), but also what they expect of others (e.g., Tajfel \& Turner, 1986). At the same time, groups frequently undergo changes and may even fall apart. The "falling apart" of groups has primarily been investigated in social psychological research on group schisms (for a summary, see Sani, 2008) and has largely been attributed to perceived changes in a group's identity.

More specifically, schism research assumes that changes occurring or decisions being made within a group are monitored concerning their fit to group members' expectations (e.g., Sani, 2008). These expectations are usually based on the group's norms, which are - in groups with a long tradition like nations - an integral part of their identity. If individuals (or members of a certain subgroup) perceive an event or decision to violate their expectations and to, thus, influence the group's identity in an undesirable way, they should experience what Sani and colleagues (e.g., Sani \& Reicher, 1999; Sani \& Todman, 2002) call identity subversion - the perception that a group's meaning and essence have been questioned, fundamentally changed, or do no longer exist (cf., Sani \& Reicher, 1998). Several correlational studies support this assumption (e.g., Sani \& Pugliese, 2008; Sani \& Reicher, 1998; Sani \& Todman, 2002). Moreover, the studies show that stronger experiences of identity subversion are positively related to schismatic intentions, supposedly because experiencing identity subversion is aversive (e.g., Sani, 2008). These schismatic intentions are usually operationalized by asking participants for their personal intentions to leave their group (e.g., Sani \& Pugliese, 2008; Sani \& Todman, 2002), and were found in political (Sani \& Pugliese, 2008) and religious groups (Sani \& Todman, 2002; for further studies showing a correlation between identity subversion and group leaving in experimental small groups and field settings, see Ditrich, Lüders, Jonas, \& Sassenberg, 2019; Ditrich \& Sassenberg, 2016; Ditrich, Scholl, \& Sassenberg, 2017).

In accordance with schism research, research on social identity management strategies (e.g., Tajfel \& Turner, 1979, 1986) suggests that leaving a group, that is, engaging in individual mobility, is one possible way to manage one's social identity. Tajfel and Turner $(1979,1986)$ assume that individual mobility occurs when the in-group compares unfavourably to an out-group on a valued dimension, thus failing to provide its members with a positive social identity, and when group boundaries are perceived as permeable. This assumption has been supported by several studies (e.g., Ellemers, 1993; Ellemers, Wilke, \& van Knippenberg, 1993; Wright, Taylor, \& Moghaddam, 1990) and differs from the identity subversion account of schism research only by the comparison standard used for evaluating the current group. Tajfel and Turner $(1979,1986)$ suggest that group members compare their in-group to an out-group. By contrast, Sani and colleagues (e.g., Sani, 2008; Sani \& Pugliese, 2008; Sani \& Reicher, 1998; Sani \& Todman, 2002) suggest that the current or anticipated state of the ingroup is compared to its ideal (or past) state. Both accounts suggest that when these comparisons yield unfavourable results, group members become inclined to leave their group because they no longer have the impression that their group provides them with a satisfactory social identity.

The EU-referendum can be construed as a particularly intriguing example of an event being evaluated concerning its fit with expectations. However, the norms that are most influential in determining these expectations may vary between individuals (even though group norms are usually shared between group members; Hogg \& Tindale, 2005): Whereas one person may see basing political decisions on accurate information as a highly relevant norm for defining 
his group (i.e., the UK), another may see having a representative democracy as a highly relevant norm for her group. Both may view the EU-referendum (and how it was carried out) negatively: The first person may emphasize that they do not think the EU-referendum was based on accurate information, while the second person may emphasize that in a representative democracy, there should not have been a referendum in the first place. In social psychological terms, this implies that both people should perceive the EU-referendum process as violating their expectations of political processes in the UK. Building on the findings from schism research outlined above, we assume that perceiving the EU-referendum as having violated expectations should be related to having the impression that the UK has fundamentally changed. This impression may (to some extent) have contributed to the surge in emigration numbers following the EU-referendum (Auer \& Tetlow, 2019), but may also be related to contemplating emigration as a first step to actually pursuing it.

Hypothesis 1: Evaluating the EU-referendum process as violating expectations should be positively related to individual mobility considerations (i.e., considering emigration from the UK), and perceived UK-identity subversion should underly this relation.

\section{Identity-Dynamics Related to Considering Collective Action}

Events violating group members' (norm-based) expectations also influence how individuals view their own relation to a certain group. More specifically, events violating norm-based expectations can lead to disidentification. For example, research suggests that group members disidentify when they are confronted with another member violating the group's norms and see no other way of distancing themselves from this person or when their group is continuously discriminated (Eidelman \& Biernat, 2003; Jasinskaja-Lahti, Liebkind, \& Solheim, 2009). These studies, however, base their conclusions on low levels of identification, which is problematic because - much as for example the absence of positive emotions does not imply the presence of negative emotions (e.g., Watson, Clark, \& Tellegen, 1988) - weak identification does not imply strong disidentification: Disidentification reflects "a negative self-defining relation to a relevant group" (Matschke \& Sassenberg, 2010, p. 892), whereas low identification reflects the absence of a relation to the group (for a detailed discussion, see Becker \& Tausch, 2014). One of the few studies that investigated actual disidentification and its relation to the violation of expectations is the study by Matschke and Sassenberg (2010), which demonstrated that rejection by a group can enhance disidentification among certain newcomers. Besides feeling negatively treated, a lack of fit between a group and a certain member has also been shown to increase disidentification (Hamstra, Sassenberg, van Yperen, Wisse, \& Rietzschel, 2015). Applied to the present context, this would mean that perceiving the EU referendum as having violated expectations should not only be positively associated with perceiving a subversion of the UK's identity, but should also be related to more disidentification from the citizens of the UK.

When group members are disidentified, this has adverse consequences for their groups. De Vreeze and Matschke (2017) showed for instance that disidentified members engage in strategic information sharing, thereby subtly hindering group success. Findings by Becker and Tausch (2014) likewise suggest that disidentified group members are inclined to actively engage against the group and to avoid contact with other members of the group. These findings suggest that group members who disidentify seek to distance and separate themselves from the group. Nonetheless, they might uphold their (negative) relation to the group until this group can be replaced by a different one, that is, until the negative social identity can be replaced by a positive one. This idea is also in agreement with social identity theory, which posits that intergroup conflict or collective action by a group within an intergroup context should be more likely when individuals strongly identify with their in-group while simultaneously perceiving the comparison to the out-group as a relevant (Tajfel \& Turner, 1979).

In the post-referendum situation in the UK, switching to an alternative (subordinate) in-group seems a viable option, and such alternative groups are readily available: the UK's constituent countries England, Scotland, Wales and Northern Ireland. These groups represent a unique opportunity to investigate the idea that disidentified group members may show collective action on behalf of alternative groups. Importantly, we herein define actions as collective when they aim at changing the conditions of an entire group (following Wright et al., 1990) - stressing the motivation underlying an action rather than the number of people engaging in it.

In the present study, we focus on Scotland. It represents an ideal case to investigate collective action from a social identity perspective, as many citizens strongly identify with Scotland (e.g., Brocklehurst, 2018; Grant et al., 2017) and it 
has a recent history of striving for independence (e.g., "indyref 2014", GOV.UK, n.d.). Taken together with the work on disidentification outlined above, this leads to our second hypothesis.

Hypothesis 2: Evaluating the EU-referendum process as violating expectations should be positively associated with intentions to engage in collective action on behalf of Scottish people (i.e., intentions to support a campaign for Scottish independence), and UK-disidentification should underly this relation.

\section{The Current Study}

This study was conducted during four consecutive days in late July 2017. By this time, Article 50 of the Lisbon treaty (stating that an EU-country may decide to leave the union) had formally been triggered: UK-politicians had officially notified the EU of the UK's intention to leave the union and roughly two years remained for negotiations. Guidelines for these negotiations had been agreed upon (European Union, 2020). On the day the study started, the second round of negotiations was concluded and British news reported on the British chief negotiator being optimistic about the outcomes of the negotiations, and on the EU-negotiators requesting more details from their British counterparts (BBC six o'clock news, 2017). In other words, the study was conducted in a very early, relatively calm phase of the Brexit negotiations. Nonetheless, Scots were in a situation in which it was sensible to contemplate whether they would support Scottish independence: After the Scottish parliament had voted in favour of making a formal request for a second referendum on Scottish independence in March, in June the First Minister of Scotland announced that she would carry on with her plans for this referendum, although with an altered time table (Cowburn, 2017).

In this situation, we tested our hypotheses that perceiving the EU-referendum process as expectancy-violating would be associated with two identity-related dynamics in our Scottish sample. Based on schism research, we assumed that it would be positively related to perceptions of UK-identity subversion, which in turn were assumed to be positively related to considering emigration (i.e., considering individual mobility, Hypothesis 1). Building on research on disidentification, we expected that it would be positively related to disidentification from citizens of the UK. In turn, UK-disidentification was expected to be positively related to support for Scottish independence in a new referendum (i.e., collective action intentions, Hypothesis 2; see Figure 1 for a conceptual diagram). To be able to test whether there are two separate paths to collective action and individual mobility considerations, we also included paths linking UK-identity subversion to collective action and UK-disidentification to individual mobility considerations and allowed for direct paths linking perceptions of expectancy-violation to individual mobility considerations and collective action intentions.

Figure 1

Conceptual Diagram of Hypothesised Relations

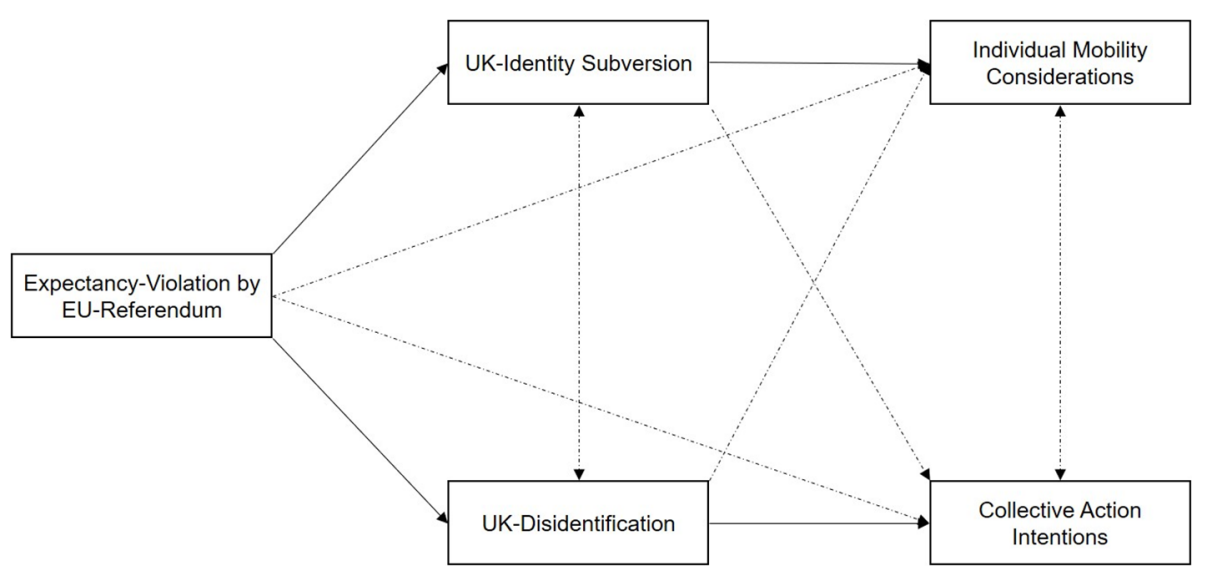

Note. Solid lines represent hypothesised relations, dashed lines represent additional relations that were modelled when testing the hypotheses. 


\section{Method}

\section{Participants and Design}

We invited all participants from the platform www.prolific.ac to participate who had indicated "Scotland" as their UK-nationality and current area of residence, as residing in Scotland was a pre-requisite to being able to vote in a (potential) referendum on Scottish independence. Two hundred and twelve participants accessed and 203 completed the online questionnaire. One participant withdrew his/her data from analyses. Therefore, all analyses reported below are based on 202 participants (83 male, 119 female, $M_{\text {age }}=36.90$, 18-84 years). Participants reported which social class they belonged to (i.e., subjective social class, SSC) by choosing one of four options: upper class (chosen by $1 \%$ ), upper middle class (12.9\%), lower middle class (40.6\%), and working class (43.6\%). Four participants did not provide information regarding their SSC.

\section{Procedure}

After accessing the online survey, participants were briefed about its general topic (i.e., perceptions of and intended reactions to Brexit), the study's duration (5-10 minutes), their rights as participants, and the anonymity of data collection. After participants had provided informed consent to participate, the measures of interest as well as some further measures were collected (for full questionnaire, see Supplementary Materials). Thereafter, participants provided basic demographic information, indicated to what extent they supported the Scottish National Party (SNP), which newspapers they favoured, and reported their own and their family's SSC, before being fully debriefed. Subsequently, participants could withdraw their data. They received $£ 1$ as compensation.

\section{Measures}

If not indicated otherwise, all measures reported below were collected using seven-point Likert-scales ranging from 1 (don't agree) to 7 (agree). Scale scores were obtained by averaging participants' responses to the respective items (after recoding inverse scored items). We decided to use short scales as described below in order to ensure participants' compliance in filling out the questionnaire.

\section{Perceptions of Expectancy-Violation by the EU-Referendum}

We define our key predictor - expectancy-violation - as participants' perception that the EU-referendum process has violated the expectations they had of political processes in the UK. As expectancy-violations usually result from a certain behaviour that is not in line with the norms one thinks apply to the given situation, our items were focused on the EU-referendum process. Moreover, we used slightly ambiguous items to make sure that we could capture expectancy-violations regardless of the norm a respondent felt was violated. In total, six items developed for this study (e.g., "In general, I think that the EU-referendum was carried out differently from how I think it should have been carried out like.") were used. However, one item ("In general, I think that the EU-referendum was carried out in a way that is typical of the UK"; reverse scored) was excluded from the scale due to a low corrected item-total-correlation (after recoding), $r(202)=-.06$. Thus, the scale consists of five items, $\alpha=.85$.

\section{UK-Identity Subversion}

Six items ( $\alpha=.90$, e.g., "The decision to leave the EU has subverted the true nature of the United Kingdom.") measured to what extent participants perceived the decision to leave the EU to subvert the identity of the UK, that is, to question or fundamentally change the essence and meaning of the UK identity (cf., Sani \& Reicher, 1998). These items were adapted from Sani and Pugliese (2008). 


\section{UK-Disidentification}

Nine items $(\alpha=.90)$ adapted from Matschke and Sassenberg (2010), Matschke and Fehr (2017), and Becker and Tausch (2014) were used to assess how strongly participants disidentified from the citizens of the United Kingdom, that is, to what extent they perceived their relation to UK-citizens as negative (e.g., "I feel alienated from the citizens of the United Kingdom.”). In addition, we also assessed UK-identification (see Supplementary Materials). A principal components factor analysis with oblimin-rotation revealed that the items measuring these two concepts loaded on separate factors. Only two disidentification items had crossloadings (.32 and .28) on the (low) identification-factor, which supports the idea that the two concepts are distinct from one another.

\section{Individual Mobility Considerations}

Four items measured to what extent participants considered emigrating from the UK, e.g., "I find the idea of a life abroad appealing". One item ("I see my long-term future in the United Kingdom."; reverse scored) was excluded from the scale due to a low corrected item-total-correlation after recoding, $r(202)=.17$. Thus, only three items formed the scale for individual mobility considerations, $\alpha=.70$.

\section{Collective Action Intentions}

Participants were asked to indicate how likely they would be to perform six different activities $(\alpha=.95)$ related to a potential future independence referendum $(1=$ extremely unlikely; 7 = extremely likely). In other words, they indicated how likely they would be to perform actions aimed at changing Scots' situation, for example vote for Scotland to leave the UK.

\section{Analysis Plan}

Originally, we planned to analyse the data with several multiple regressions, but the more parsimonious test of our predictions is obviously to test one path model using structural equation modelling. Therefore, we do not report our original power analysis, but followed the recommendations for path models by Muthén and Muthén (2002). First, we provide information on the statistical power that could be achieved with our sample size given the empirical effect sizes. Second, we provide information on how high power would have been had all assumed relations been of medium size.

Subsequently, we provide information on our main hypothesis tests. We hypothesized that perceptions of expectancy-violation would be related to UK-identity subversion and UK-disidentification, which in turn would be related to individual mobility considerations and collective action intentions, respectively (i.e., we expected two indirect effects). To test these hypotheses, we created a saturated path model in which perceptions of expectancy-violation served as the predictor, UK-identity subversion and UK-disidentification served as parallel mediators, and individual mobility as well as collective action intentions served as outcome variables. We allowed for correlations between the two mediators, the two outcomes, and for direct relations between our predictor and the two outcomes. We employed MPlus (version 8.1, Muthén \& Muthén, 1998-2017) using a maximum likelihood estimation (maximum number of iterations: 5000), computed bias-corrected confidence intervals based on 5000 bootstrap samples, and report standardized path estimates ( $\beta$; i.e. MPlus STDYX standardization).

Finally, the results of comparative analyses of model fit are described. To this end, we specified different models analogous to our key hypothesized model and tested their fit to the data.

\section{Results}

\section{Power}

We conducted a power analysis using a Monte Carlo simulation with 500 replications, treating estimates obtained in the main analysis (but with $z$-standardized variables) as a proxy for the population parameters. This analysis suggests that the present study had over $99.9 \%$ power to detect an effect of $\beta=0.37$ (i.e., the size of the indirect effect of 
expectancy-violation on individual mobility considerations via UK-identity subversion) and had $99.6 \%$ power to detect an effect of $\beta=0.19$ (i.e., the size of the indirect effect of expectancy-violation on collective action intentions via UK-disidentification).

To gain more insight into the power that could be achieved with our sample, an additional simulation was run. It assumed that $4 \%$ of the variance in each of the dependent variables (UK-identity subversion, UK-disidentification, collective action intentions, individual mobility considerations) is explained by the model, that the hypothesized relations are small $(\beta=0.20)$, and that all remaining paths are 0 . This simulation indicated that with $N=202,78.6 \%$ to $84.6 \%$ power could be achieved to detect small direct relations between the variables of interest. This leads us to conclude that our study was adequately powered.

\section{Main Analysis}

Descriptive statistics and information on variable intercorrelations are provided in Table 1. In line with our hypotheses, our results suggest that perceptions of the EU-referendum as violating expectations were positively associated with perceptions of UK-identity subversion, $\beta=0.73, S E=0.05, z=15.73, p<.001,95 \% \mathrm{CI}[0.62,0.80]$, as well as UK-disidentification, $\beta=0.34, S E=0.07, z=5.14, p<.001,95 \%$ CI [0.21, 0.47]; see Figure 2 .

Table 1

Descriptive Statistics and Intercorrelations for Key Variables

\begin{tabular}{|c|c|c|c|c|c|c|}
\hline Key Variable & $M$ & $S D$ & 2 & 3 & 4 & 5 \\
\hline 1. Expectancy-violation by EU referendum & 4.23 & 1.55 & $.73^{* * *}$ & $.34^{* * *}$ & $.18^{*}$ & $.43^{* * *}$ \\
\hline 2. UK-Identity subversion & 4.89 & 1.58 & - & $.32^{* * *}$ & $.16^{*}$ & $.55^{* * *}$ \\
\hline 3. UK-Disidentification & 3.38 & 1.24 & & - & $.56^{* * *}$ & $.26^{* * *}$ \\
\hline 4. Collective action intentions & 3.24 & 2.04 & & & - & $.14^{*}$ \\
\hline 5. Individual mobility considerations & 5.02 & 1.52 & & & & - \\
\hline
\end{tabular}

${ }^{*} p<.05 .{ }^{* *} p<.01 .{ }^{* * *} p<.001$.

\section{Figure 2}

Standardized Relationships (Standard Errors in Parentheses) Between Perceptions of the EU-Referendum as an Expectancy-Violation, UK-Disidentification, UK-Identity Subversion, Collective Action Intentions, and Individual Mobility Considerations, Including Residual Variances

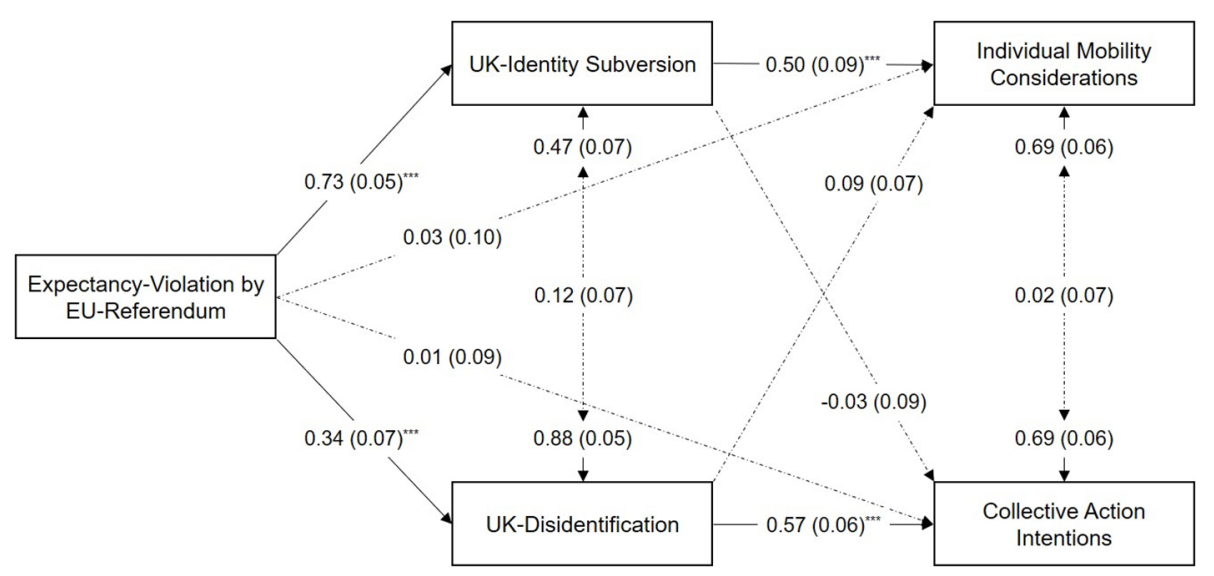

Note. Solid lines represent significant relations, dashed lines represent non-significant relations.

In line with Hypothesis 1, we found a significant relation between perceiving the EU-referendum as an expectancy violation and individual mobility considerations, $\beta=0.43, S E=0.07, z=5.79, p<.001,95 \% \mathrm{CI}[0.28,0.56]$, which was reduced to non-significance when the mediators were included, $\beta=0.03, S E=0.10, z=0.33, p=.740,95 \%$ CI $[-0.16$, 
0.24]. Further supporting Hypothesis 1 , we found evidence consistent with a mediation (an indirect only mediation according to Zhao et al., 2010) by UK-identity subversion, $\beta=0.37, S E=0.07, z=5.49, p<.001,95 \% \mathrm{CI}[0.24,0.49]$, but no evidence consistent with a mediation by UK-disidentification, $\beta=0.03, S E=0.03, z=1.19, p=.233,95 \% \mathrm{CI}[-0.01,0.09]$.

Perceiving the EU-referendum as an expectancy-violation was also significantly related to collective action intentions, $\beta=0.18, S E=0.07, z=2.47, p=.014,95 \% \mathrm{CI}[0.04,0.31]$. When the mediators were included, this relation was reduced to non-significance, $\beta=0.01, S E=0.09, z=0.05, p=.958,95 \% \mathrm{CI}[-0.17,0.17]$. We found no evidence consistent with a mediation by UK-identity subversion, $\beta=-0.02, S E=0.07, z=-0.35, p=.729,95 \%$ CI [-0.14, 0.12]. However, in line with Hypothesis 2, we found evidence consistent with a (indirect only) mediation by UK-disidentification, $\beta=0.19$, $S E=0.04, z=4.73, p<.001,95 \% \mathrm{CI}[0.12,0.28]$.

Taken together, these results support our hypotheses by showing that perceiving the EU-referendum as having violated expectations was indeed positively related to individual mobility considerations, mediated via UK-identity subversion (Hypothesis 1), and to collective action intentions, mediated via UK-disidentification (Hypothesis 2). Residual variances of the two mediators (UK-identity subversion, UK-disidentification) and the two outcomes (individual mobility considerations, collective action intentions) were not significantly correlated, all $p s>.085$. Thus, the at first sight counterintuitive positive correlation between individual mobility considerations and collective action intentions displayed in Table 1 seems to be due to their shared correlate: perceiving the EU-referendum as an expectancy-violation. This lends further support to our proposed model.

\section{Model Comparisons}

To test whether our proposed model fits the data better than possible alternative models, we ran several analyses based on the same overall pattern (one predictor, two mediators, two outcomes), changing which variable was used as predictor and which as mediators. We did not specify a correlation between the mediators (thus constraining it to 0 ), to obtain one free parameter for model fit assessment. Table 2 provides an overview of the tested models and their fit parameters.

Table 2

Fit Indices for Hypothesized Model and Alternative Models (Without Requesting Covariances Between Mediators)

\begin{tabular}{|c|c|c|c|c|c|c|c|c|c|c|}
\hline \multirow[b]{2}{*}{ No. } & \multirow[b]{2}{*}{ Predictor } & \multirow[b]{2}{*}{ Parallel Mediators } & \multirow[b]{2}{*}{ Outcomes } & \multirow[b]{2}{*}{ AIC } & \multirow[b]{2}{*}{$\chi^{2}(1) ; p$} & \multicolumn{3}{|c|}{ RMSEA } & \multirow[b]{2}{*}{ CFI } & \multirow[b]{2}{*}{ SRMR } \\
\hline & & & & & & Estimate & $90 \% \mathrm{CI}$ & $\begin{array}{c}\quad p \\
\text { (RMSEA } \\
\leq \mathbf{0 . 0 5 )}\end{array}$ & & \\
\hline 1 & $\begin{array}{l}\text { Expectancy-violation by } \\
\text { EU referendum }\end{array}$ & $\begin{array}{l}\text { - UK-identity } \\
\text { subversion } \\
\text {. UK-disidentification }\end{array}$ & $\begin{array}{l}\text { - Individual mobility } \\
\text { considerations } \\
\text { - Collective action } \\
\text { intentions }\end{array}$ & 2720.00 & $2.67 ; .102$ & 0.09 & $0.00 ; 0.23$ & .187 & 1.00 & 0.023 \\
\hline 2 & UK-identity subversion & $\begin{array}{l}\text { Expectancy-violation } \\
\text { by EU referendum } \\
\text { - UK-disidentification }\end{array}$ & $\begin{array}{l}\text { - Individual mobility } \\
\text { considerations } \\
\text { - Collective action } \\
\text { intentions }\end{array}$ & 2714.83 & $5.50 ; .019$ & 0.15 & $0.05 ; 0.28$ & .052 & 0.99 & 0.029 \\
\hline 3 & UK-disidentification & $\begin{array}{l}\text { - UK-identity } \\
\text { subversion } \\
\text { - Expectancy-violation } \\
\text { by EU referendum }\end{array}$ & $\begin{array}{l}\text { - Individual mobility } \\
\text { considerations } \\
\text { - Collective action } \\
\text { intentions }\end{array}$ & 2940.49 & $133.82 ;<.001$ & 0.81 & $0.70 ; 0.93$ & $<.001$ & 0.59 & 0.163 \\
\hline
\end{tabular}

Note. No. $=$ Model number; Criteria for good model fit: $\chi^{2} p>.05 ;$ RMSEA $\leq 0.06$; CFI $\geq 0.95$; SRMR $\leq 0.08$ (Hu \& Bentler, 1999).

Model comparisons indicate that the proposed model (minus the correlation between the mediators; Model No. 1) fits the data well, as three out of the four fit indices indicate good model fit based on the criteria outlined by Hu and Bentler (1999). Compared to a model in which UK-identity subversion acts as the predictor (Model No. 2), the proposed model has a slightly higher AIC, implying that it might be less parsimonious and provide a worse fit to the data than this 
alternative model. However, only CFI and SRMR suggest that Model No. 2 fits the data well and RMSEA is higher than for Model No. 1, which leads us to conclude that Model No. 2 is inferior to our proposed model despite its slightly better AIC. For Model No. 3, both AIC and the fit indices suggest inadequate model fit and a lack of parsimony compared to our proposed model. We interpret these comparison results as support for the accuracy of our model.

Finally, as previous work frequently explored effects on and of disidentification by means of assessing reduced identification, we computed an additional analysis adding UK-identification as an additional mediator along with the mediators included in our main analysis. The result pattern remained unchanged and we found no evidence that UK-identification acts as an additional mediator in our model (for details, see Supplementary Materials).

\section{Discussion}

The outcome of the EU-referendum in 2016 has sparked numerous protests across a time span of three and a half years (e.g., Agerholm, 2017; BBC News, 2016; Merrick, 2019; Stone \& Foster, 2016; Telegraph Reporters, 2017), culminating in silent vigils in one place and celebrations in another on January, 31, 2020, when the UK officially left the EU (e.g., BBC News, 2020b). This suggests that the decision to leave the EU was far from being unanimously supported. The current study focused on Scots, a majority of whom had voted "remain", and explored how they dealt with the situation in July 2017. Specifically, we explored which identity-dynamics were associated with the referendum and how those related to individual mobility considerations (i.e., considering emigration) and collective action intentions (i.e., intentions to support a campaign in favour of Scottish independence). We hypothesized that intentions to show both identity management strategies would be positively related to respondents' impression that the EU-referendum violated expectations they had formed based on their subjective representation of the norms defining UK politics. Moreover, we assumed that different dynamics would underlie these relations. Both assumptions were supported in a survey study conducted in an early phase of the Brexit negotiations. Our results show that participants with a stronger impression that the EU-referendum violated their expectations concerning political processes in the UK reported stronger individual mobility considerations and collective action intentions. These relations were mediated by two different factors.

The relation between perceiving the EU-referendum as an expectancy-violation and individual mobility considerations was mediated by perceptions of UK-identity subversion, that is, by the perception that the outcomes of the referendum have fundamentally changed what it means to be a UK-citizen. This finding replicates previous social psychological research on group schisms (for a summary, see Sani, 2008) regarding individualized intentions to leave a group. However, contrary to the argumentation underlying schism research that identity subversion should be positively related to members of a sub-group joining forces in seceding from a superordinate group (which would reflect a true schism as defined by Sani \& Reicher, 1998, p. 624), the current work does not provide evidence for a relation between identity subversion and collective action. This might be due to a difference in measures: While in schism research, participants are often asked whether they individually seceded from a group or intend to do so, we asked for explicit actions on behalf of an alternative group. This suggests that the processes motivating sub-group members to join forces in an effort at collectively changing their sub-group's standing might be even more complex than schism research suggests.

The relation between perceptions of expectancy-violation and collective action intentions was mediated by disidentification from the citizens of the UK. Our results suggest that experiencing a political event as violating expectations is related to collective action intentions (i.e., intentions to change a [sub-]group's situation) because such events are associated with group members perceiving a negative relation to the (superordinate) group. The potential consequences of this perceived negative relation to a group have, to date, been largely neglected by research on social identity management strategies. In relation to this field of research, the current study can thus be seen as a first step to filling an important research gap, as it investigated group members' choice of a specific social identity management strategy while taking into account disidentification (i.e., a negative relationship to a group). Furthermore, the present findings provide a first indication that also intra-group dynamics may render the identity a group provides its members with unsatisfactory, which motivates group members to show identity management attempts. Future research on social 
identity management strategies, hence, may seek to systematically investigate how intra-group dynamics interact with socio-structural variables in influencing group members' choice of a specific social identity management strategy.

Regarding research on disidentification, a noteworthy strength of our study is that we employed actual measures of disidentification instead of basing our conclusions on low levels of identification. We found that events within a group that are perceived as violating expectations are positively related to disidentification, thereby conceptually replicating previous findings (Eidelman \& Biernat, 2003; Jasinskaja-Lahti et al., 2009; Matschke \& Sassenberg, 2010) in a very different setting.

When looking at our measures, however, two potential issues come to mind. First, it may be deemed problematic that our measure of expectancy-violation focused on procedural aspects of the referendum rather than on its outcome. This approach was chosen as, from a social identity perspective, expectations often rest on norms prescribing and describing certain behaviours for group members (e.g., Sherif, 1961; Terry \& Hogg, 1996). Thus, for expectations to be violated, a certain behaviour or event needs to occur. Moreover, as our measure of UK-identity subversion already assesses a very specific outcome of the referendum's result, assessing expectancy-violation with a focus on the referendum's result would likely have artificially increased the correlation between the two measures. Nonetheless, future research may need to include a broader measure of expectancy-violations.

Second, it might be speculated that participants who had been critical of the UK already before the referendum, for example Scottish nationalists, may have responded differently to our measure of UK-identity subversion. However, our data do not provide sufficient evidence to support this idea (see Supplementary Materials). Specifically, we find no moderating effects of identification as Scottish, support for the SNP, or identification as a UK-citizen on the relations between expectancy-violation and any other variable in our model. If anything, the relation between UK-disidentification and collective action intentions increased with increasing support for the SNP (for details, see Supplementary Materials). Moreover, a strong identification with their (sub-)group as evidenced by our sample seems to be rather typical for Scots (e.g., Brocklehurst, 2018; Grant et al., 2017). Nonetheless, it might be interesting to test the dynamics investigated herein with a more polarized sample.

If future research is conducted to further investigate the identity-dynamics discussed, it may seek to address an important limitation of the current work: its correlational, cross-sectional nature. Our results are based on a single survey administered at one point in time and rely on participants' self-reports. Hence, when we speak about predictors, mediators, and outcomes, these terms are purely based on theoretical reasoning. We would argue that the model comparisons showing a superior fit of the proposed model compared to various alternative models speak in favour of its validity and against assumptions of reverse causation. However, we can certainly not rule out the influence of potential unassessed third variables. Thus, to further explore the processes identified herein, future research may seek to longitudinally follow the development of a group, as experimentally inducing the investigated dynamics seems problematic not least from an ethical point of view. Additionally, future research might also try to obtain more objective measures of individual mobility considerations (e.g., by longitudinally recording actual emigration) and collective action intentions (e.g., by investigating voting behaviour), to address the limitation of self-reports. What needs to be considered, however, is that the results of such an endeavour (or even of a replication of the present study) likely depend strongly on the time of data collection. Data collected during a more heated period of the Brexit negotiations or closer in time to the formal Brexit might yield stronger relations between the concepts. In both cases, we would expect identity concerns to be even more salient and considerations of what to do to be even more relevant than they were when the present study was conducted. Even though (the strength of) the relations investigated herein, thus, might vary depending on the time point of data collection, we nonetheless think that the present study offers important insights into the psychological aspects of geopolitical events for identity researchers and policy makers alike.

The present findings show that how a political event (or the process leading up to it) is perceived is closely tied to how people intend to react: The more respondents in the present study had the impression that their expectations had been violated by the EU-referendum, the more inclined they were to consider both emigration and collective action. This finding may be particularly relevant to policy makers, as both of these reactions can potentially harm a society: While considerations of and actual emigration could have adverse economic effects especially if young, well-educated citizens emigrate, collective action (on behalf of a sub-group within a larger group) may contribute to social division and unrest. This has two implications. First, policy makers from a subordinate group may strive to strategically construe the 
decisions and behaviours of policy makers from the superordinate group as violating expectations to rally members of the subordinate group to their cause. Second, and conversely, policy makers from the superordinate group may strive to prevent their behaviours and decisions from being viewed as violating expectations. This might be accomplished by rhetorically construing controversial decisions as consistent with a group's norms and identity: Policy makers may seek to actively (re-)define what is normative for their group and thereby "manage" the group's identity (e.g., Hogg \& Reid, 2006). Admittedly, this might be very difficult to accomplish in political settings, as in these, a unified group whose identity to "manage" rarely exists. Nonetheless, knowing that decisions might not only be judged based on their tangible political and economic consequences, but also based on the intangible norms people assume to be characteristic of the political landscape they live in could prove valuable for policy makers.

The current study additionally shows that concerns about group memberships and social identities are not only relevant for the political decisions people make (e.g., Abrams \& Travaglino, 2018; Manners, 2018) but also for how they react to political events. Thereby, they further social-psychological research on geopolitical events and Brexit in particular, by suggesting that identity related concerns might need to be considered when seeking to understand the consequences of such events.

To conclude, the current study suggests that two factors need to be considered when trying to understand the identity-related dynamics that, for Scots, were associated with the post-referendum situation in the UK: identity subversion and disidentification from the citizens of the UK. These dynamics were associated with different behavioural tendencies. A stronger impression that the EU-referendum's outcomes had fundamentally changed what it means to be British was associated with a stronger consideration of emigrating from the UK, while feeling bad about being a citizen of the UK was related to stronger intentions to support a campaign for Scottish independence. These findings demonstrate the pervasive role identity processes will play in shaping the future of the post-referendum UK, thereby complementing earlier findings (e.g., Abrams \& Travaglino, 2018; Manners, 2018; Swami et al., 2018; Van de Vyver et al., 2018) which show that identity processes also shaped voting decisions in the EU-referendum itself.

Funding: The authors have no funding to report.

Competing Interests: The authors have declared that no competing interests exist.

Acknowledgments: The authors wish to thank Margarete Ocker for proof-reading an earlier version of this manuscript and Nora Umbach for her statistical advice.

Author Note: The research presented in this manuscript was carried out during the second author's internship at the Leibniz-Institut für Wissensmedien.

Data Availability: Data and code for this publication are available in the open access repository PsychArchives (Ditrich, Gedeon, \& Sassenberg, 2020a, 2020b).

\section{Supplementary Materials}

The following Supplementary Materials for this publication are available via the PsychArchives repository (for access see Index of Supplementary Materials below):

- Research data and codebook

- Code

- Additional analyses and questionnaire

\section{Index of Supplementary Materials}

Ditrich, L., Gedeon, E. Z., \& Sassenberg, K. (2020a). Supplementary materials to "Favouring a disunited Kingdom? How negative perceptions of the EU-referendum relate to individual mobility and collective action considerations" [Research data and codebook]. PsychOpen. https://doi.org/10.23668/psycharchives.4276 
Ditrich, L., Gedeon, E. Z., \& Sassenberg, K. (2020b). Supplementary materials to "Favouring a disunited Kingdom? How negative perceptions of the EU-referendum relate to individual mobility and collective action considerations" [Code]. PsychOpen. https://doi.org/10.23668/psycharchives.4277

Ditrich, L., Gedeon, E. Z., \& Sassenberg, K. (2021). Supplementary materials to "Favouring a disunited Kingdom? How negative perceptions of the EU-referendum relate to individual mobility and collective action considerations" [Additional analyses and questionnaire]. PsychOpen. https://doi.org/10.23668/psycharchives.4548

\section{References}

Abrams, D., \& Travaglino, G. A. (2018). Immigration, political trust, and Brexit - Testing an aversion amplification hypothesis. British Journal of Social Psychology, 57, 310-326. https://doi.org/10.1111/bjso.12233

Agerholm, H. (2017, September 9). Thousands of anti-Brexit protesters march on Parliament. The Independent. Retrieved from http://www.independent.co.uk/news/uk/home-news/brexit-march-protesters-parliament-thousands-parliament-square-peopleseurope-a7937571.html

Auer, D., \& Tetlow, D. (2019, October 28). Guest Blog: More Britons willing to leave UK to escape Brexit uncertainty [Blog Post]. Retrieved from https://www.compas.ox.ac.uk/2019/brexit-uncertainty-motivates-risk-taking-by-brits-who-decide-to-leave-the-uk-and-theresusually-no-turning-back

BBC News. (2016, July 2). Thousands at 'March for Europe' Brexit protest. Retrieved from http://www.bbc.com/news/uk-36692990

BBC News. (2018). EU referendum results. Retrieved from http://www.bbc.com/news/politics/eu_referendum/results

BBC News. (2020a, January 29). Scottish independence: MSPs back new referendum in Holyrood vote. Retrieved from https://www.bbc.com/news/uk-scotland-scotland-politics-51284836

BBC News. (2020b, February 1). Vigils and celebrations as Scots mark Brexit day. Retrieved from https://www.bbc.com/news/uk-scotland-51325766

BBC six o'clock news [Audio File]. (2017, July 20). Retrieved from https://www.bbc.co.uk/programmes/b08xxdq7

Becker, J. C., \& Tausch, N. (2014). When group memberships are negative: The concept, measurement, and behavioral implications of psychological disidentification. Self and Identity, 13, 294-321. https://doi.org/10.1080/15298868.2013.819991

Blanz, M., Mummendey, A., Mielke, R., \& Klink, A. (1998). Responding to negative social identity: A taxonomy of identity management strategies. European fournal of Social Psychology, 28, 697-729. https://doi.org/10.1002/(SICI)1099-0992(199809/10)28:5<697::AID-EJSP889>3.0.CO;2-\#

Brocklehurst, S. (2018, June 6). Ten things we learned about Scottishness. Retrieved from https://www.bbc.com/news/uk-scotland-44208691

Cowburn, A. (2017, March 28). Scottish referendum: Scottish parliament votes in favour of holding second independence referendum. The Independent. Retrieved from https://www.independent.co.uk/news/uk/politics/scottish-independence-referendum-indyref-2-nicola-sturgeon-vote-date-latesta7654591.html

de Vreeze, J., \& Matschke, C. (2017). Keeping up appearances: Strategic information exchange by disidentified group members. PLoS One, 12, Article e0175155. https://doi.org/10.1371/journal.pone.0175155

Ditrich, L., Lüders, A., Jonas, E., \& Sassenberg, K. (2019). Leader's group-norm violations elicit intentions to leave the group - If the group-norm is not affirmed. Journal of Experimental Social Psychology, 84, Article 103798. https://doi.org/10.1016/j.jesp.2019.03.009

Ditrich, L., \& Sassenberg, K. (2016). It's either you or me! Impact of deviations on social exclusion and leaving. Group Processes \& Intergroup Relations, 19, 630-652. https://doi.org/10.1177/1368430216638533

Ditrich, L., Scholl, A., \& Sassenberg, K. (2017). Time to go! Leaving the group in response to norm-deviations. Journal of Experimental Social Psychology, 73, 259-267. https://doi.org/10.1016/j.jesp.2017.07.005

Eidelman, S., \& Biernat, M. (2003). Derogating black sheep: Individual or group protection? fournal of Experimental Social Psychology, 39, 602-609. https://doi.org/10.1016/S0022-1031(03)00042-8 
Electoral Commission. (2018). Electoralcommission.org.uk. Retrieved February 12, 2018 from https://www.electoralcommission.org.uk/find-information-by-subject/elections-and-referendums/past-elections-andreferendums/eu-referendum/electorate-and-count-information

Ellemers, N. (1993). The influence of socio-structural variables on identity management strategies. European Review of Social Psychology, 4, 27-57. https://doi.org/10.1080/14792779343000013

Ellemers, N., Wilke, H., \& van Knippenberg, A. (1993). Effects of the legitimacy of low group or individual status on individual and collective status-enhancement strategies. fournal of Personality and Social Psychology, 64, 766-778. https://doi.org/10.1037/0022-3514.64.5.766

European Union. (2020). Brexit Timeline. Retrieved from https://www.consilium.europa.eu/en/policies/eu-uk-after-referendum GOV.UK. (n.d.). Scottish independence referendum. Retrieved from

https://www.gov.uk/government/topical-events/scottish-independence-referendum

GOV.UK. (2014). Scottish independence referendum: Our place in the world. Retrieved from

https://www.gov.uk/government/publications/scottish-independence-referendum-our-place-in-the-world/scottish-independencereferendum-our-place-in-the-world

Grant, P. R., Bennett, M., \& Abrams, D. (2017). Using the SIRDE model of social change to examine the vote of Scottish teenagers in the 2014 independence referendum. British fournal of Social Psychology, 56, 455-474. https://doi.org/10.1111/bjso.12186

Hamstra, M. R. W., Sassenberg, K., van Yperen, N. W., Wisse, B., \& Rietzschel, E. F. (2015). Regulatory fit buffers against disidentification from groups. Motivation Science, 1, 184-201. https://doi.org/10.1037/mot0000019

Hogg, M. A., \& Reid, S. A. (2006). Social identity, self-categorization, and the communication of group norms. Communication Theory, 16, 7-30. https://doi.org/10.1111/j.1468-2885.2006.00003.x

Hogg, M. A., \& Tindale, R. S. (2005). Social identity, influence, and communication in small groups. In J. Harwood \& H. Giles (Eds.), Intergroup communication: Multiple perspectives (pp. 141-164). New York, NY, USA: Peter Lang.

Hu, L. T., \& Bentler, P. M. (1999). Cutoff criteria for fit indexes in covariance structure analysis: Conventional criteria versus new alternatives. Structural Equation Modeling, 6, 1-55. https://doi.org/10.1080/10705519909540118

Jasinskaja-Lahti, I., Liebkind, K., \& Solheim, E. (2009). To identify or not to identify? National disidentification as an alternative reaction to perceived ethnic discrimination. Applied Psychology, 58, 105-128. https://doi.org/10.1111/j.1464-0597.2008.00384.x

Lewis, G. J., \& de-Wit, L. (2019). How many ways to say goodbye? The latent class structure and psychological correlates of European Union sentiment in a large sample of UK adults. fournal of Social and Political Psychology, 7, 556-576. https://doi.org/10.5964/jspp.v7i1.981

Manners, I. (2018). Political psychology of European integration: The (re)production of identity and difference in the Brexit debate. Political Psychology, 39, 1213-1232. https://doi.org/10.1111/pops.12545

Matschke, C., \& Fehr, J. (2017). Does identity incompatibility lead to disidentification? Internal motivation to be a group member acts as buffer for sojourners from independent cultures, whereas external motivation acts as buffer for sojourners from interdependent cultures. Frontiers in Psychology, 8, Article 335. https://doi.org/10.3389/fpsyg.2017.00335

Matschke, C., \& Sassenberg, K. (2010). Does rejection lead to disidentification? The role of internal motivation and avoidance strategies. European fournal of Social Psychology, 40, 891-900. https://doi.org/10.1002/ejsp.756

Merrick, R. (2019, February 16). Brexit: Put It To The People march demanding Final Say referendum to take place six days before UK leaves EU. The Independent. Retrieved from

https://www.independent.co.uk/news/uk/politics/brexit-march-final-say-referendum-parliament-theresa-may-peoples-votea8782791.html

Muthén, L. K., \& Muthén, B. O. (1998-2017). Mplus User’s Guide (8th ed). Los Angeles, CA, USA: Muthén \& Muthén.

Muthén, L. K., \& Muthén, B. O. (2002). How to use a Monte Carlo study to decide on sample size and determine power. Structural Equation Modeling, 9, 599-620. https://doi.org/10.1207/S15328007SEM0904_8

Peitz, L., Dhont, C., \& Seyd, B. (2018). The psychology of supranationalism: Its ideological correlates and implications for EU attitudes and post-Brexit preferences. Political Psychology, 39, 1305-1322. https://doi.org/10.1111/pops.12542

Sani, F. (2008). Schism in groups: A social psychological account. Social and Personality Psychology Compass, 2, 718-732. https://doi.org/10.1111/j.1751-9004.2007.00073.x

Sani, F., \& Pugliese, A. C. (2008). In the name of Mussolini: Explaining the schism in an Italian right-wing political party. Group Dynamics, 12, 242-253. https://doi.org/10.1037/1089-2699.12.3.242 
Sani, F., \& Reicher, S. (1998). When consensus fails: An analysis of the schism within the Italian Communist Party (1991). European fournal of Social Psychology, 28, 623-645. https://doi.org/10.1002/(SICI)1099-0992(199807/08)28:4<623::AID-EJSP885>3.0.CO;2-G

Sani, F., \& Reicher, S. (1999). Identity, argument and schism: Two longitudinal studies of the split in the Church of England over the ordination of women to the priesthood. Group Processes \& Intergroup Relations, 2, 279-300.

https://doi.org/10.1177/1368430299023005

Sani, F., \& Todman, J. (2002). Should we stay or should we go? A social psychological model of schisms in groups. Personality and Social Psychology Bulletin, 28, 1647-1655. https://doi.org/10.1177/014616702237646

Sherif, M. (1961). Conformity-deviation, norms, and group relations. In I. A. Berg \& B. M. Bass (Eds.), Conformity and deviation (pp. 159-198). New York, NY, USA: Harper and Brothers.

Sirois, F. M., \& Iyer, A. (2018). "At least David Cameron resigned”: The protective effects of just-world beliefs for counterfactual thinking after Brexit. Personality and Individual Differences, 121, 25-30. https://doi.org/10.1016/j.paid.2017.09.015

Smith, D. S. (2019). Shaping the modern world with a stone-age brain: The Brexit referendum and the moral foundations theory. fournal of Social and Political Psychology, 7, 863-889. https://doi.org/10.5964/jspp.v7i2.1032

Stone, J., \& Foster, K. (2016, July 2). Brexit protest: Tens of thousands march through London calling for UK to remain in EU. The Independent. Retrieved from

http://www.independent.co.uk/news/uk/home-news/brexit-eu-referendum-protest-march-30000-anti-saturday-2-july-angerbanners-leave-vote-central-a7115646.html

Swami, V., Barron, D., Weis, L., \& Furnham, A. (2018). To Brexit or not to Brexit: The roles of Islamophobia, conspiracist beliefs, and integrated threat in voting intentions for the United Kingdom European Union membership referendum. British fournal of Psychology, 109, 156-179. https://doi.org/10.1111/bjop.12252

Tajfel, H., \& Turner, J. C. (1979). An integrative theory of intergroup conflict. In W. G. Austin \& S. Worchel (Eds.), The social psychology of intergroup relations (pp. 33-47). Monterey, CA, USA: Brooks/Cole.

Tajfel, H., \& Turner, J. C. (1986). The social identity theory of intergroup behavior. In S. Worchel \& W. G. Austin (Eds.), Psychology of intergroup relations (2nd ed., pp. 7-24). Chicago, IL, USA: Nelson-Hall Publishers.

Telegraph Reporters. (2017, September 9). Brexit protest: 'Incompetent, dysfunctional, disunited': Vince Cable tears into Theresa May's government. The Telegraph. Retrieved from http://www.telegraph.co.uk/news/2017/09/09/anti-brexit-protesters-take-streets-thousands-expected-london

Terry, D. J., \& Hogg, M. A. (1996). Group norms and the attitude-behavior relationship: A role for group identification. Personality and Social Psychology Bulletin, 22, 776-793. https://doi.org/10.1177/0146167296228002

Van de Vyver, J., Leite, A. C., Abrams, D., \& Palmer, S. B. (2018). Brexit or Bremain? A person and social analysis of voting decisions in the EU referendum. Journal of Community \& Applied Social Psychology, 28, 65-79. https://doi.org/10.1002/casp.2341

Watson, D., Clark, L. A., \& Tellegen, A. (1988). Development and validation of brief measures of positive and negative affect: The PANAS scales. Journal of Personality and Social Psychology, 54, 1063-1070. https://doi.org/10.1037/0022-3514.54.6.1063

Wright, S. C., Taylor, D. M., \& Moghaddam, F. M. (1990). Responding to membership in a disadvantaged group: From acceptance to collective protest. Journal of Personality and Social Psychology, 58, 994-1003. https://doi.org/10.1037/0022-3514.58.6.994

Zhao, X., Lynch, J. G., Jr., \& Chen, Q. (2010). Reconsidering Baron and Kenny: Myths and truths about mediation analysis. fournal of Consumer Research, 37, 197-206. https://doi.org/10.1086/651257 